\title{
"We were treated like adults"-development of a pre-medicine summer school for 16 year olds from deprived socioeconomic backgrounds: action research study
}

Trisha Greenhalgh, Jill Russell, Lisa Dunkley, Petra Boynton, Frances Lefford, Nikhil Chopra

\begin{abstract}
Objective To develop a one week widening access summer school for 16 year old pupils from non-traditional backgrounds who are considering applying to medical school, and to identify its short term impact and key success factors.

Design Action research with partnership schools in deprived inner city areas in five overlapping phases: schools liaison, recruitment of pupils and assessment of needs, programme design, programme delivery, and evaluation. The design phase incorporated findings from one to one interviews with every pupil, and workshops and focus groups for pupils, parents, teachers, medical student assistants, NHS staff, and other stakeholders. An in-depth process evaluation of the summer school was undertaken from the perspective of multiple stakeholders using questionnaires, interviews, focus groups, and observation.

Participants 40 pupils aged 16 years from socioeconomically deprived and under-represented ethnic minority groups. Results The summer school was popular with pupils, parents, teachers, and staff. It substantially raised pupils' confidence and motivation to apply to medical school. Critical success factors were identified as an atmosphere of "respect"; a focus on hands-on work in small groups; the input of medical students as role models; and vision and leadership from senior staff. A particularly popular and effective aspect of the course was a grand round held on the last day, in which pupils gave group presentations of real cases.

Conclusion An action research format allowed us to draw the different stakeholders into a collaborative endeavour characterised by enthusiasm, interpersonal support, and mutual respect. The input from pupils to the programme design ensured high engagement and low dropout rates. Hands-on activities in small groups and social drama of preparing and giving a grand round presentation were particularly important.
\end{abstract}

\section{Introduction}

"Widening access" programmes designed to increase applications to medical school from "non-traditional" pupils (that is, those from lower socioeconomic backgrounds, certain ethnic minority groups, and those whose parents did not attend university) have had mixed success. ${ }^{12}$ The failure of such pupils to apply to medical school, and to stay the course once accepted, is mainly to do with lack of confidence, lack of support, low motivation, unrealistic images of medicine and medical school, and thinking of themselves as "not a university type."3-6
We developed a widening access summer school for pupils from under-represented groups to encourage application to medical school and measured its impact on participants and staff. We also identified aspects of the programme that were critical to its success with a view to replicating these in other settings.

\section{Methods}

Study design

The study linked educational development and research by drawing on the principles of action research. ${ }^{7}$ This is an emergent approach, in which data are systematically and successively gathered to develop a picture of the problem and inform the next phase of action. We have previously reported a preliminary scoping phase on the views of 15 year old non-traditional pupils towards medicine and medical school. ${ }^{6}$ We now report on the development, delivery, and evaluation of a summer school for 16 year olds. The figure and the table summarise the phases of the study.

\section{Management and governance}

All core staff and assistants were cleared by the Criminal Records Bureau. A broad-based steering group was established with representation from funders, participating schools, the local NHS trust, medical students from University College London, and evaluators.

\section{Schools liaison}

We used a database of "partnership" schools in inner London, which were already being visited by UCL medical students as part of a separate mentoring project. We identified key contacts (heads of science or careers officers) and interviewed eight of them. We also discussed the project with six head teachers at a local authority training day. In these discussions, we set the following eligibility criteria for pupils: attending a participating school; recommended by a teacher, based on assessment of motivation and ability (GCSE predictions of A grades in maths and science plus B in English); and parents did not go to university. We also used the index of multiple deprivation score, derived from the pupil's home postcode, to prioritise applicants from the most deprived backgrounds (see box A on bmj.com).

Recruitment of pupils and assessment of needs We asked teachers to approach selected pupils individually and invite them to apply. Of 70 nominated pupils, 41 were offered

Details of using the IMS score, suggestions for improving the scheme, and quotes from pupils are on bmj.com. 


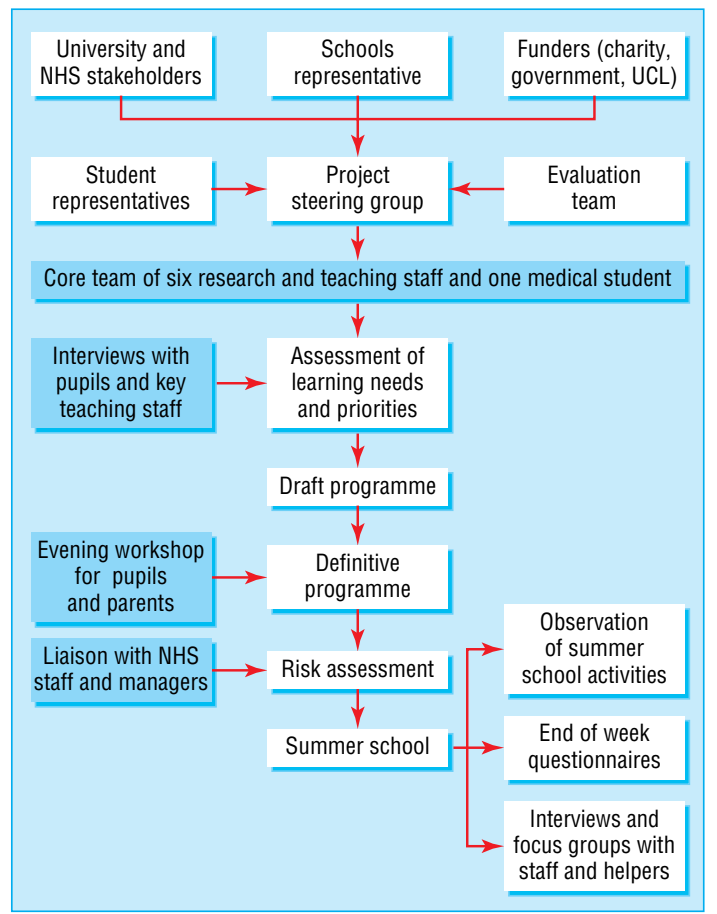

Summary of project design and methods

places and all accepted them, though one withdrew because of illness. Twenty seven of the 29 pupils who we turned down were refused places because both parents had been to university, they had relatively affluent backgrounds (as measured by the index of multiple deprivation of their home postcode), or they lived outside London.

Thirty eight of the 41 accepted pupils attended a UCL "partnership" school (non-selective state school with a traditionally low application rate to higher education). All accepted pupils were predicted by their teachers to gain A grades in maths and science at GCSE; 33 lived in an area that lay in the lowest quarter nationally for socioeconomic deprivation; and in 31, neither parent had been to university. Seventeen $(41 \%)$ were male. Sixteen

\section{Box 1: Outline interview schedule for interviews}

Tell me about your life so far. Start with when you were born, and just carry on

Tell me about how you see the future

\section{About your interest in medicine}

What do you think about medicine as a career option for you? What do you know about medical school?

Where did you get your information about medical school? What are your own chances of (a) getting in and (b) passing the course and becoming a doctor?

How do you think you will do at interview?

If you didn't end up doing medicine, where do you think you will end up?

\section{About the summer school}

What sort of things do you hope to do at the summer school?

Do you have any concerns about coming on the summer school?

were first generation immigrants, and a further 18 were the children of immigrants, comprising eight from Africa and the Caribbean, 14 from Asia, and 13 from Europe and the Mediterranean. The cohort was drawn from 19 different countries of origin and spoke 16 ethnic languages (including Turkish, Farsi, Albanian, Arabic, Sylheti, Somalian, and Cantonese, which are the seven languages identified by local primary care trusts as the most needed in healthcare consultations).

We interviewed consenting pupils (40 of the 41 ) with the outline schedule (box 1). Interviews were audiotaped, transcribed, and analysed thematically. ${ }^{8}$ Each pupil also submitted a one page personal statement as part of their application, which we analysed by content analysis. ${ }^{9}$ We presented a summary of findings to the project steering group, our team of medical student assistants at a half day workshop, and pupils and their parents at an evening meeting (which all but one pupil attended). Through their feedback, we developed and refined the programme for the summer school.

\begin{tabular}{|c|c|c|c|c|}
\hline Phase & Goals & Main actions & Data sources & Key findings \\
\hline $\begin{array}{l}\text { Schools liaison (month } \\
1-3 \text { ) }\end{array}$ & $\begin{array}{l}\text { Identify and build relationships with } \\
\text { partnership schools; estimate level of } \\
\text { interest; identify challenges }\end{array}$ & $\begin{array}{l}\text { Interviews with teachers, } \\
\text { careers officers, and local } \\
\text { education authority's widening } \\
\text { participation officers }\end{array}$ & $\begin{array}{l}\text { UCL's existing database of local secondary } \\
\text { schools in deprived inner city areas } \\
\text { ("partnership schools"); field notes from } \\
\text { visits to schools; interview notes }\end{array}$ & $\begin{array}{l}\text { Many interested local schools; staff highly } \\
\text { motivated but have multiple competing } \\
\text { priorities; project aligned well with wider goals } \\
\text { for post-16 education locally and nationally }\end{array}$ \\
\hline $\begin{array}{l}\text { Recruitment of pupils } \\
\text { (month 3-8) }\end{array}$ & $\begin{array}{l}\text { Seek applications; ascertain eligibility; } \\
\text { identify pupils' hopes, fears, and } \\
\text { expectations about medicine in general } \\
\text { and summer school in particular }\end{array}$ & $\begin{array}{l}\text { Work with key contacts in } \\
\text { participating schools to identify } \\
\text { suitable pupils; confirm } \\
\text { "non-traditional" background; } \\
\text { interview every pupil } \\
\text { individually }\end{array}$ & $\begin{array}{l}\text { Semistructured (qualitative) interviews with } \\
40 \text { of } 41 \text { pupils, taped and transcribed; } \\
\text { written personal statement from all pupils; } \\
\text { demographic data from application form } \\
\text { (postcode, whether parents went to } \\
\text { university, ethnicity); publicly available } \\
\text { database of index of multiple deprivation } \\
\text { scores by postcode }\end{array}$ & $\begin{array}{l}33 \text { of } 41 \text { pupils lived in the lowest quarter of } \\
\text { socioeconomic deprivation; pupils lacked } \\
\text { confidence and understated their } \\
\text { achievements; surgery, accident and } \\
\text { emergency, and high technology specialties } \\
\text { predominated in pupils' perceptions and } \\
\text { expectations }\end{array}$ \\
\hline Design (month 7-11) & $\begin{array}{l}\text { Plan summer school in liaison with } \\
\text { pupils and parents }\end{array}$ & $\begin{array}{l}\text { Develop draft programme; seek } \\
\text { input from pupils and parents } \\
\text { in refining programme; train } \\
\text { staff }\end{array}$ & $\begin{array}{l}\text { Sticky notes and flip chart paper from pupil } \\
\text { and parent workshops; feedback from staff } \\
\text { and medical student training sessions; risk } \\
\text { assessment in liaison with local education } \\
\text { authority officers }\end{array}$ & $\begin{array}{l}\text { Hands-on, confidence building activities } \\
\text { required small groups and high staff to pupil } \\
\text { ratio; watching operations was possible with } \\
\text { meticulous planning and prior risk assessment }\end{array}$ \\
\hline Delivery (month 12) & Deliver summer school & $\begin{array}{l}\text { Run summer school; capture } \\
\text { process data }\end{array}$ & $\begin{array}{l}\text { Ethnographic observation of all sessions by } \\
\text { qualitative researchers; documentation of } \\
\text { tasks and challenges by all team members }\end{array}$ & $\begin{array}{l}\text { Culture of "respect" in which pupils are } \\
\text { expected to work independently and creatively } \\
\text { in small groups was a powerful context for } \\
\text { learning and personal development }\end{array}$ \\
\hline $\begin{array}{l}\text { Evaluation (month } \\
10-16 \text { ) }\end{array}$ & Evaluate summer school & $\begin{array}{l}\text { Collate and sort previously } \\
\text { collected process data; capture } \\
\text { reflections of pupils, parents, } \\
\text { and staff after summer school }\end{array}$ & $\begin{array}{l}\text { All above, plus pupil and parent evaluation } \\
\text { forms; semistructured survey of teachers } \\
\text { and guest tutors; focus groups for staff } \\
\text { and medical student assistants }\end{array}$ & $\begin{array}{l}\text { Summer school was seen as a successful } \\
\text { educational opportunity by pupils, parents, } \\
\text { and staff; its longer term impact has not yet } \\
\text { been established }\end{array}$ \\
\hline
\end{tabular}




\section{Key design points for the summer school}

When first interviewed, pupils had few clear ideas about what the summer school should contain. They had a somewhat ill formed desire to "talk to lots of people," "meet real students," and "see/do what real doctors do." As in our previous research, ${ }^{6}$ these pupils lacked confidence and substantially underestimated their chances of getting into medical school. Their personal statements understated their achievements and failed to mention personal strengths-for example, over half of the bilingual pupils did not mention their language skills.

Teachers confirmed these impressions. One described the three key barriers to these pupils' low success rate as "lack of self determination, lack of confidence, and lack of information." Teachers did not see the purpose of the summer school as remedying individual academic weaknesses but as exposing the pupils to real world medicine, boosting self esteem, and prompting action.

Pupils' perceptions of medicine were heavily biased towards acute surgical specialties, and they had limited knowledge of (or interest in) primary health care, prevention, chronic care, or rehabilitation. While we felt compelled to try to redress this bias, we also wanted to base the summer school around an image of medicine that was meaningful to the pupils. We arrived at the key design features of the summer school through the consultation process (box 2).

\section{Programme design}

We addressed non-cognitive objectives (in relation to self esteem, confidence, motivation, peer support, etc) by basing the programme around small groups with medical student assistants present as "buddies." We asked medical students to nominate suitable guest tutors (kind, supportive, inspirational) from the medical school faculty, each of whom was invited to lead a 90 minute hands-on session, preferably with a real patient. In consultation with guest tutors, we developed objectives and structured lesson plans that reflected key priorities identified in our thematic analysis (for example, watching operations, meeting transplant patients). We undertook a detailed risk assessment, for which a separate report is available.

\section{Programme delivery}

The full timetable is available from the authors. After an interactive orientation and objective setting plenary session, around $90 \%$ of the taught programme was delivered in small groups by guest tutors, with medical students acting as mentors, guides, and troubleshooters. We took pupils out of the timetabled activities

\section{Box 2: Key design features of summer school identified} in initial interviews and stakeholder consultation

The summer school should:

- Promote confidence, motivation, and the development of professional identity

- Provide opportunities for developing friendships and peer support networks

- Expose pupils to a wide range of medical student and medical role models, if possible from appropriate social, ethnic, and sex backgrounds

- Provide an "insider view" on acute specialties (for example, surgery) but also enlighten pupils about the breadth of medicine (for example, laboratory specialties, preventive care, chronic disease management, and general practice)

- Provide guidance on practical issues (financial planning, constructing personal statements, interviews) two at a time to watch an operation. At the end of the day students were debriefed in small groups. One specific activity designed to develop peer group bonding and boost confidence was the grand round (box 3).

\section{Evaluation}

JR and FL evaluated the summer school from the perspective of pupils, parents, teachers, medical student assistants, patients, and others. The key questions addressed were:

- What did they consider to be the main successes, weaknesses, important features, and critical processes of the summer school?

- What were the key strategic and operational challenges?

- What is the nature of the social and educational processes during the school and how do these processes impact on pupils during the week?

We drew on the theoretical principles of illuminative evaluation proposed by Parlett and Hamilton. ${ }^{10}$ This approach is concerned more with description and interpretation than measurement and prediction. In illuminative evaluation there are three characteristic stages: researchers observe, inquire further, and then seek to explain. The methods used were:

- Ethnographic observation of the project steering group and planning meetings, group sessions, and informal observation of participants (for example, chatting to pupils during refreshment breaks)

- Evaluation forms given to all pupils and parents at the end of the week, which sought free text responses on questions such as "what three words you would use to describe the experience," "what were the best things about the summer school," and "how you would change it" and included rating scales to assess overall value and impact on confidence

\section{Box 3: The grand round-building confidence through a complex group task}

The grand round was held in a lecture theatre on the final day of the course. Each group of 10 pupils had to describe the history of a real patient and present relevant investigations, treatment plans, and the patient's progress. To prepare for their presentation, each group of 10 pupils was required to:

- Interview a real patient in-depth about his or her illness and the impact it has had

- Divide up the tasks of finding x ray films, ECG recordings, histology slides, and other relevant materials from different hospital departments

- Collect the empty boxes for the patient's medication and find out the action and side effects of each drug

- Look up the "evidence base" for the patient's management with the help of a librarian

- Work together to collate all these into a PowerPoint presentation

- Address issues of patient confidentiality (for example, gaining consent, anonymising data)

- Allocate presentation roles and practise their presentation to achieve the 15 minute time limit

- Present to an audience that included medical students and senior doctors as well as parents, teachers, and careers officers.Various staff around the hospital and medical school were primed to assist with the preparation of the grand round, and many prepared material in advance to supply to the pupils when they visited the relevant department. The grand round thus took on the aura of an escalating (and highly competitive) treasure hunt that built up over the week, with each group adding material to its presentation during lunch and tea breaks, and developing creative ideas for outperforming the other groups 
- One focus group for medical student assistants (held on the last day of the summer school) and another for core staff (held the following week)

- Semistructured questionnaires to guest tutors and key contact teachers.

Copies of the evaluation forms are available on request. We analysed the field notes, transcripts of focus groups, and free text responses on evaluation forms using a standard thematic approach for qualitative data, ${ }^{8}$ and synthesised key themes by reflection and discussion. We circulated a draft report to all core staff, members of the steering group, and participating schools to check the interpretation of data and develop the analysis further. The report was also made available to pupils at a reunion three months after the summer school, and they were invited to send in comments.

\section{Results}

\section{Main findings from the evaluation}

Thirty five of 40 pupils, 18 of 40 parents, 13 of 23 guest tutors, and 5 of 14 school contacts returned questionnaires after the summer school, and one additional teacher sent an unsolicited letter of thanks. Overall, feedback was extremely positive, and pupils thought that all their objectives had been met. The following quote from a pupil is typical:

"It's a fantastic opportunity and a truly amazing experience that I am grateful to have been a part of as I am now prepared for university and am reassured about going into medicine."

All but three thought their confidence had increased. One pupil added:

"I loved the way this project transformed us all. Some were less confident than others (for example, I wasn't so confident speaking in front of an audience or to patients), but I've overcome this, plus I've learnt some really impressive things-how to read a CT scan, how to relate to patients."

Parents and teachers also commented on pupils' increased confidence. One teacher thought that " ... as a result of attending summer school, pupils will happily go off to lectures at other institutions on their own next year."

Many guest tutors and medical student assistants commented on pupils' high level of engagement. Only two of 40 pupils withdrew, and attendance for all sessions was close to $100 \%$. The medical students were impressed by the pupils' level of maturity and "the extent to which they really wanted to learn." Guest tutor comments included:

\footnotetext{
“There wasn't any of this subversive, sitting at the back, I'm not taking part in this. With a group of 4016 -year olds you would expect a bit more of that."

"I found the students in my group uniformly keen, polite, intelligent, and sensible. It was hard to believe they were only 15-16 year olds."

"What surprised me was the extent to which the students were focused on preparing for their grand round tasks. Their motivation was really high with this task-they were working together as teams and really dynamic in their approach. This was very impressive."
}

Table A on bmj.com lists the most important things pupils thought they had learnt at the summer school.

The evaluators identified four key critical success factors from the evaluation data:

The fostering of respect-Pupils greatly valued their views being taken seriously and being treated "like responsible adults in a hospital." A core tutor said, "There was constant reinforcement during the week that we believed in them."

The input of medical student assistants-Pupils described them as "helpful, motivating, and inspirational."

The value of working in small groups-described by pupils as "fantastic," "fun," "motivating," "made me want to learn," "increased my confidence," as well as many comments that "ours was the best group."

The vision and leadership of senior staff was also important.

The detailed observation (and reflective discussion by the core team) of what actually happened in the development and delivery of the summer school provided unique insights into why and how the critical success factors arose and how they achieved their impact. For example, "respect" was probably achieved through the linkages we had made with schools, the strong personal recommendations that school teachers provided in support of particular pupils, and the preliminary interviews and workshops in which pupils had shared their personal stories. Pupils' high motivation was probably attributable to preparatory work done by the teachers who had nominated them, to their feeling part of the design of the course, and to the expectation that they would work independently and creatively in their small groups.

The medical students supported and enriched the pupils' learning by developing close and trusting relationships with their groups, helping tutors in teaching sessions, and (perhaps most importantly) joining in informal discussions and activities. The type of knowledge imparted by students was sometimes factual (such as explaining what aortic stenosis is), but was more often experiential (such as, "I've failed exams but they don't throw you out"). Furthermore, they personalised advice so as to make it relevant for the individual and context (such as, "I wouldn't wear that T shirt for Dr X's session" or "you should put your pharmacy job on your personal statement").

The medical students were an important driver for the strong sense of commonality and camaraderie between pupils, which emerged through what one of the pupils described as "working with a great group of peers who share the same passion and dreams as me." Through close daily contact with their "buddies," pupils learnt that medical students are "normal" and, importantly, that "you don't need to be a super genius or come from a wealthy background to be a doctor." One student reflected afterwards, "I'm from a similar background to most of the kids here ... I wanted to show them all the right bits to do in order to get in, not to be put down by anyone."

Perhaps the key dimension of "leadership and vision" as a critical success factor was the energy and commitment with which senior staff visited schools to capture pupils' and teachers' priorities and tailored the course accordingly (for example, by building in a strong focus on developing pupils' confidence). A careers officer wrote "it's to your eternal credit that you turned talk into action. I've helped out a lot of people with research projects and most of it never leads to anything."

The evaluation identified many suggestions (mostly operational and administrative) for improving the course (see box B on bmj.com).

\section{Discussion}

The research and policy literature on widening access emphasises the high academic potential of many non-traditional pupils, ${ }^{11}{ }^{12}$ their low application rates to university, ${ }^{11}{ }^{13}$ and high dropout rates. ${ }^{11}$ It suggests a large untapped reservoir of non-traditional pupils who have much to offer but whose 
commitment is fragile and who require enrichment and support to make it to, and through, university.

Three things surprised us about these pupils: their interest, maturity, and commitment to the course, which was present from the outset and which inspired respect from faculty and hospital staff; the dramatic growth in pupils' confidence through the week; and the development of close friendships and peer support networks within the small groups.

Bruner (among others) has criticised the literature on educational attainment in underprivileged children for conceptualising the problem as a "deficit" in the child that must be made good. ${ }^{14}$ Writing mainly about US enrichment programmes for the under 5 s, he argues that so called "deprived" learners actively seek experiences and strive to make sense of, and achieve mastery of, the world around them; it is the environment that we should think of as requiring enrichment, not the learner. Our experience with these pupils, who engaged enthusiastically with the design of the summer school and seized the opportunities they had helped create, strongly supports this conceptual model.

Bloom proposed that educational experiences have three dimensions: cognitive (imparting knowledge), psychomotor (acquiring skills), and affective (changing attitudes and motivation). ${ }^{15}$ The literature on group work in educational settings suggests that the small group format is not especially effective in achieving cognitive objectives but is highly effective in developing complex skills and in changing the attitudes and perspectives that underpin learning and make it meaningful. ${ }^{16}$ The mechanisms for this may include

- Social modelling (observing peers behaving in a certain way or expressing particular views $)^{17}$-for example, learning elementary "bedside manners"

- Vicarious experience (being inspired to action (or put off) by what happened to someone else) ${ }^{17}$-for example, watching someone struggle with questions in a mock interview

- Development of social capital (such as friends, contacts, and local knowledge $)^{18} 19$

- Collective sense making (in which the group questions, negotiates, and reframes the meaning of information until it is expressed in a way that is acceptable, meaningful, and sensible $)^{20}$ - Transmission and personalisation of "tacit" knowledge (that is, practical knowhow that is difficult to articulate formally and that you don't often find in books) ${ }^{21} 22$

- Reframing of identity (for example, from "someone who isn't a university type" to "someone who is" ${ }^{23}$ )

- Social drama (the group members being caught up in a real unfolding story $)^{24}$-for example, in the grand round task.

We found no evidence in these pupils of anti-academic values or attempts to subvert the educational aims of the summer school. In our own previous research, both these themes had been prominent in white and African-Caribbean boys volunteering for pre-medicine activities. ${ }^{6}$ Other researchers have described anti-academic values and subversive behaviour in boys of both white ${ }^{5}$ and mixed ethnicity ${ }^{3}$ in the UK and in (mostly white) girls in the US..$^{25}$ We believe that inviting teachers personally to nominate individual pupils for a limited number of places served to filter out disaffected and half hearted pupils. This probably means that despite our best efforts, we have still failed to access a cohort of able pupils who have been "turned off" academic career options before the age of 16 . Further research with younger age groups is needed to explore this hypothesis.

In conclusion, we have shown that it is feasible to work in partnership with aspiring applicants to medical school from socioeconomically deprived backgrounds and with no family tradition of higher education to design and deliver a successful

\section{What is already known on this topic}

Pupils from poor backgrounds, certain ethnic groups, and those whose parents did not go to university are less likely to apply to medical school and more likely to drop out

"Widening access" initiatives to increase application and subsequent retention in such groups have had mixed success

\section{What this study adds}

Action research can be used to engage schools and pupils in the design and delivery of a summer school

Hands-on activities in small groups and a "grand round" in which all pupils participate are effective learning methods

Close contact with medical student "buddies" can boost confidence and motivation

short term educational opportunity. We have identified what we consider are the critical success factors of such a programme and predict that, if these can be replicated, the summer school should be broadly transferable to other settings. But we have not yet shown a long term impact of this initiative on pupils' identity, confidence, motivation, or action. We are continuing to follow these pupils as they enter the sixth form and begin to construct their applications to medical school, and we hope to publish data at a later stage on their success rates and subsequent progress.

We congratulate the pupils who participated in the Dick Whittington project for their enthusiasm and hard work. We thank all participating schools for their engagement and collaboration and Mohammed Lais for help with interviews. The summer school could not have been possible without the positive support and cooperation of the management and staff of the Whittington Hospital Trust and especially the many clinicians who served as guest tutors. We are extremely grateful to our three sponsors who provided funding and active input to the project steering group.

Contributors: TG initially conceptualised the study, which was subsequently refined by all authors as part of the action research process. TG, LD, PB, and NC interviewed pupils and analysed data from these. NC developed and implemented the scoring system for socioeconomic deprivation. His input formed the dissertation for an intercalated BSc at UCL. JR developed and led the evaluation with assistance from FL. All authors sat on the steering group and were involved in delivering the summer school. TG wrote the paper with input from all authors and is guarantor.

Funding: Sutton Trust, Department of Education and Skills (via Islington 14-19 Pathfinder), UCL Widening Participation Fund.

Competing interests: None declared.

Ethical approval: Approval was obtained from NHS and university research ethics committees.

1 Secretary of State for Education. Medical schools: delivering the doctors of the future. London: Department for Education and Skills, 2004

Terrell C, Beaudreau J. 3000 by 2000 and beyond: next steps for promoting diversity in the health professions. J Dent Educ 2003;67:1048-52.

3 Archer L, Hutchings M. Bettering yourself? Discourses of risk, cost and benefit in young workArcher L, Hutchings M. Bettering yourself? Discourses of risk, cost and benefit in young work-
ing class non-participants' constructions of higher education. London: STORM, University of ing class non-participants
North London, 2000.

North London, 2000.
Bordieu P, Passeron JC. Reproduction in education, society and culture. London: Sage, 1990.

Bordieu P, Passeron JC. Reproduction in education, society and culture. London: Sage, 1990.
Willis P. Learning to labour: how working class kids get working class jobs. Farnborough: Willis P. Learning to
Saxon House, 1977.

Saxon House, 1977.
Greenhalgh T, Sevan K, Boynton P. "Not a university type": focus group study of social class, ethnic, and sex differences in school pupils' perceptions about medical school. BMJ 2004;328:1541.

7 Waterman H, Tillen D, Dickson R, de Koning K. Action research: a systematic review and guidance for assessment. Health Technol Assess 2001;5:iii-157.

8 Green J, Thorogood N. Oualitative methods for health research. London: Sage, 2004.

9 Green J, Thorogood N. Qualitative methods for health research. London: Sage, 2004. Y, eds. Handbook of qualitative research. London: Sage, 2005.

10 Parlett M, Hamilton D. Evaluation as illumination: a new approach to the study of innovatory programmes. In: Hamilton D, ed. Beyond the numbers game: a reader in educational evaluation. London: Macmillan, 1972. 


\section{Research}

11 Universities UK. Fair enough: wider access to university by identifying potential to succeed. London: Universities UK, 2003.

12 Department of Health. Drive for more doctors and nurses from deprived backgrounds: New plans to train more underprivileged students. Press release 10 August 2004. www.dh.gov.uk/PublicationsAndStatistics/PressReleases/fs/en (accessed 14 February 2006).

13 Council of Heads of Medical Schools. Medical education and research: CHMS statement of principles. www.chms.ac.uk/key_prin.html (accessed 14 February 2006).

14 Bruner J. The culture of education. London: Harvard University Press, 1997.

15 Bloom BS. Taxonomy of educational objectives. Boston, MA: Allyn and Bacon, 1984.

16 Elwyn G, Greenhalgh T, Macfarlane F. Groups-a hands-on guide to small group work in education, management and research. Oxford: Radcliffe, 2000.

17 Bandura A. Social foundations of thought and action: a social cognitive theory. Englewood Cliffs, NJ: Prentice-Hall, 1986.

18 Schuller T, Preston J, Hammond C, Brasset-Grundy A, Bynner J. The benefits of learning. The impact of education on health, family life and social capital. London: Routledge Farmer 2004.

19 Wenger E. Communities of practice: learning, meaning and identity. Cambridge: Cambridge University Press, 1996.

20 Weick KE. Sensemaking in organizations. Thousand Oaks, CA: Sage, 1995.

21 Polanyi M. The tacit dimension. New York: Anchor Day, 1962.
22 Fraut M. Non-formal learning, implicit learning and tacit knowledge. In: Coldfield F, ed. Informal learning. Bristol: Policy Press, 1999.

Goffman $\mathbf{E}$ The presentation of self in everyday life New York: Penguin, 1969

24 Turner V. Social dramas and stories about them. Critical Inquiry 1980;7:141-68.

25 Brown LM. Raising their voices: the politics of girls' anger. London: Harvard University Press, 1998.

(Accepted 22 December 2005)

doi $10.1136 /$ bmj. 38755.582500 .55

Department of Primary Care and Population Sciences, University College London, London N19 5LW

Trisha Greenhalgh professor of primary health care

Jill Russell non-clinical lecturer

Petra Boynton non-clinical lecturer

Frances Lefford GP tutor

Nikhil Chopra medical student

Academic Centre for Medical Education, London N19 5LW

Lisa Dunkley clinical lecturer

Correspondence to: T Greenhalgh p.greenhalgh@pcps.ucl.ac.uk 